\title{
A Rare Case of Idiopathic Congenital Complete Heart Block in a Neonate
}

\author{
Sinha $\mathbf{R}^{1}$, Negi $\mathbf{V}^{2}$, Dalal $\mathbf{S S}^{3}$ \\ ${ }^{1}$ Dr. Rahul Sinha, MBBS, MD, DNB Department of Paediatrics, 167 Military Hospital, Pathankot, Punjab, ${ }^{2}$ Dr. Vandana Negi, \\ MBBS, MD, DM (Neonatology), Department of Paediatrics, Army Hospital (R\&R), New Delhi. ${ }^{3}$ Dr. Shamsher Singh Dalal, \\ MBBS, MD, DM (Neonatology), Command Hospital Air Force, Bangalore, India.
}

Address for correspondence: Dr. Rahul Sinha, E-mail: drrahul_2000@yahoo.com

\begin{abstract}
Congenital complete heart block in utero has become diagnosed more frequently with the clinical use of fetal echocardiography. Autoimmune-associated congenital complete heart block (CHB) is a rare but important disease that can now be diagnosed in utero using fetal echocardiography ${ }^{1,2,3,4}$. The overall incidence of isolated CHB has been reported to be approximately 1:15,000 to 20,000 live births ${ }^{5}$. Several reviews have shown that children diagnosed prenatally have an increased mortality compared to those diagnosed immediately after birth or later in childhood ${ }^{1,2,3,4}$. At birth, some neonate with complete heart block may remain asymptomatic and may not require a pacemaker but majority require pacemaker to increase the heart rate. We report a rare case of idiopathic congenital complete heart block in a newborn male.
\end{abstract}

\section{Introduction}

C ongenital complete heart block in utero has become diagnosed more frequently with the clinical use of fetal echocardiography. The fetus with complete heart block may remain asymptomatic or may develop congestive heart failure. Autoimmune-associated congenital complete heart block $(\mathrm{CHB})$ is a rare but important disease that can now be diagnosed in utero using fetal echocardiography ${ }^{1,2,3,4}$. The overall incidence of isolated CHB has been reported to be approximately $1: 15,000$ to 20,000 live births ${ }^{5}$. Several reviews have shown that children diagnosed prenatally have an increased mortality compared to those diagnosed immediately after birth or later in childhood ${ }^{1,2,3,4}$. Most of the deaths in CHB patients occur in early infancy; however, there have been in utero deaths reported. Fetuses and infants at risk include those with hydrops fetalis, those with low ventricular rates, and those born prematurely. Congenital complete heart block is more frequently seen in infants of mothers with systemic lupus erythematosus, both clinically manifested and subclinical systemic lupus erythematosus with positive antibodies (SS-A and SS-B antibodies). At birth, some neonate with complete heart block may remain asymptomatic and may not require a pacemaker but majority require pacemaker to increase the heart rate. We report a rare case of idiopathic congenital complete heart block in a newborn male.

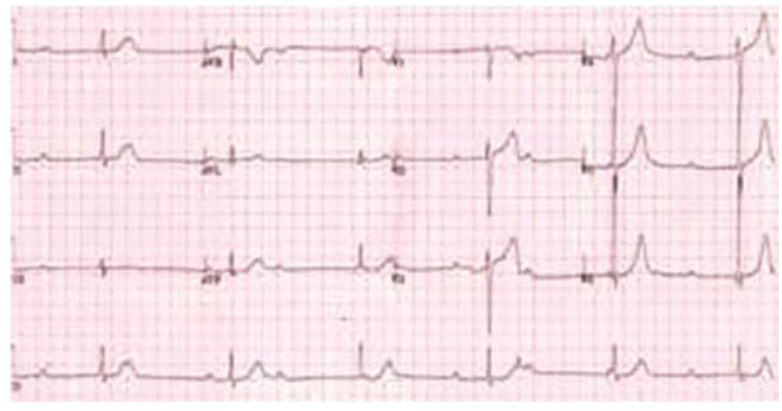

Fig 1: ECG showing complete heart block

\section{The Case}

A 2300gms preterm (34weeks) male neonate was delivered by emergency caesarean section( Indication: fetal bradycardia with fetal distress). The baby did not cry immediately after birth and had bradycardia (HR- 40/ min). The CPR was started with bag and mask ventilation with $100 \%$ oxygen and chest compression but there was no improvement, the baby was intubated and CPR continued but there was no increase in heart rate and baby was limp and cyanosed. The ECG monitor showed complete heart block with ventricular rate around 45 beats/min (Fig 1). Injection adrenaline was given but there was minimal response. The baby was shifted to NICU and was started on mechanical ventilation, ionotropic support, antibiotics and calcium. 
In antenatal history, mother is 24 years old primigravida booked and immunized with no risk factors. The entire workup for TORCH/HIV/VDRL/HBsAg and connective tissue disorder was negative. Her blood group was A +ve. The initial ultrasound scan was normal. She presented at 34 weeks period of gestation with decreased fetal movements. The ultrasound and Doppler study showed fetal bradycardia with fetal ascites. It was decided to take her up for emergency caesarean section.

The sepsis screen/ IgM for TORCH titres/anti SS-A/ Ro and anti SS-B/La was negative. The renal function and liver function test was normal. The CXR/USG (abdomen/ cranium) was normal. The ECG showed complete heart block (fig 1). The Echocardiography did not show any structural heart defect. The condition of the baby worsened after $12 \mathrm{hrs}$ of birth, developed poor perfusion, further decrease in heart rate and skin mottling. There was no nearby facility for pacemaker insertion and baby finally succumbed to the illness after $18 \mathrm{hrs}$ of birth. The main aim of this case reporting is to keep the possibility of idiopathic congenital heart block when all the work up is negative.

\section{Discussion}

The incidence of congenital complete heart block has been estimated to be about 1 out of 22,000 live births $^{6,7}$. Approximately $25 \%$ to $33 \%$ of all congenital complete heart blocks are associated with congenital heart disease. The most common among these associated lesions is an L-transposition of the great arteries. The association of collagen vascular disease in mothers of infants with congenital complete heart block, either overt or subclinical, was first reported by McCue et al. The presence of SS-AIRo or SS-B/La antibodies in mothers and neonates with complete heart block has been clearly documented.' These antibodies are IgG, can cross the placenta, and appear in the fetus at around the 16th week of gestation; all fetuses are not affected. Other factors that could be responsible for the development of congenital complete heart block are HLA type, timing of antibody transfer, and in-utero environment. The presence of certain HLA types (HLA-DR3, B8, DRW52, and DQW2) in the mother and fetus increase the possibility of complete heart block. Lev postulated a lack of union between the AV node and the His bundle. Other abnormalities reported are interruption of the AV node and abnormal conduction system. Other situations facilitating a diagnosis of complete heart block include a routine fetal echocardiogram to rule out congestive heart disease, evaluation of an immune hydrops, or ultrasound evaluation of fetal distress presented with fetal bradycardia. In-utero congestive heart failures with ventricular dysfunction, hydrops, and fetal deaths have been reported. The clinical features of the neonate depend on the effect of heart rate on cardiac output.
At birth, the infant may present with congestive heart failure, anasarca, hepatomegaly, and metabolic acidosis requiring emergent pacing. Not all neonates will require treatment. Some are asymptomatic and usually have a ventricular rate $>55$ beats/minute. The neonate with associated congenital heart disease has a much different prognosis. Mortality is high, even with appropriate therapy. In-utero management of fetuses with complete heart block in heart failure is extremely difficult. Administrations of various medications to the mother and transuterine fetal cardiac pacing have been tried without success. Carreira et all' reported a fetus with systemic lupus erythematosus myocarditis and congenital complete heart block in congestive heart failure treated with a high dose of dexamethasone. The heart failure from myocarditis disappeared at birth; however, the heart block persisted. Plasmapheresis has been recommended to limit congestive heart failure but it is unsuccessful in reversing established fetal heart block. The prophylactic use of plasmapheresis for prevention of the development of congenital complete heart block is a theoretical consideration of the immunopathology of this condition. Most of the maternal lgG reaches the fetus in the third trimester in pregnancy. It is not confirmed when congenital complete heart block occurs, but most cases are detected at 20 weeks of gestation.

Fetal complete heart block cannot be diagnosed by electrocardiogram through the mother's abdomen. However, in labor with the head engaged, an electrode can be placed in the fetal scalp to make a definitive diagnosis of complete heart block. With the recent advent of fetal echocardiography, the atrial and ventricular rates and their relationship can be determined to confirm the diagnosis of complete heart block. To date, various medications to the mother, in-utero invasive procedures, or plasmapheresis to the mother have been sporadically successful in the management of fetuses with complete heart block in heart failure. The management of fetuses with in utero congestive heart failure from complete heart block needs further investigation. Our case might have benefited with pacemaker insertion as there was no obvious cause for the complete heart block.

\section{References}

1. Buyon JP, Hiebert R, Copel J, et al. Autoimmuneassociated congenital heart block: demographics, mortality, morbidity and recurrence rates obtained from a national neonatal lupus registry. J Am Coll Cardiol 1998;31:1658-1666.

2. Eronen M, Siren MK, Ekblad H, Tikanoja T, Julkunen $\mathrm{H}$, Paavilainen T. Short and long-term outcome of children with congenital complete heart block diagnosed in utero or as a newborn. Pediatrics 2000;106:86-91. 
3. Groves AMM, Allan LD, Rosenthal E. Outcome of isolated congenital complete heart block diagnosed in utero. Heart 1996;75:190-194.

4. Jaeggi ET, Hamilton RM, Silverman ED, Zamora SA, Hornberger LK. Outcome of children with fetal, neonatal or childhood diagnosis of isolated congenital atrioventricular block. J Am Coll Cardiol 2002;39:130-137.
5. Michaelsson M, Engle MA. Congenital complete heart block: an international study of the natural history. Cardiovasc Clin 1972;4:85-101.

6. Camm AJ, Bexton RS. Congenital heart block. Eur Heart J 1984; 5:115-117.

7. McCue CM, Mantakas ME, Tinglestad JB, Ruddy S. Congenital heart block in newborns of mothers with connective tissue disease. Circulation 1977; 56:82-87.

\section{How to cite this article ?}

Sinha R, Negi V, Dalal SS. A Rare Case of Idiopathic Congenital Complete Heart Block in a Neonate. J Nepal Paediatr Soc 2012;32(2):163-165. 